\title{
Developing an Interactive Computer Program for Integrated Dental Education
}

\author{
Ava K. Chow*, Nazlee Sharmin* \\ School of Dentistry, Faculty of Medicine and Dentistry, College of Health Sciences, University of Alberta, Edmonton, Canada
}

Objectives: The knowledge of anatomy is an integral part of dental and medical education that builds the foundations of pathology, physiology, and other related disciplines. Traditional three-dimensional (3D) models used to teach anatomy cannot represent dynamic physiological processes and lack structural detail in the oral regions relevant for dental education. We developed an interactive computer program to teach oral anatomy, pathology, and microbiology in an integrated manner to improve students' learning experiences. Methods: The computer program, Jawnatomy, was developed as a 3D human head. Cognitive load theory guided the design of the tool, with the goal of reducing the heavy cognitive load of learning anatomy and integrating this knowledge with pathology and microbiology. Keller's attention, relevance, confidence, and satisfaction (ARCS) model of motivational design was used while creating the tool to improve learners' motivation and engagement. Blender was used to create the graphics, and Unity 3D was used to incorporate interactivity in the program. The 3D renderings of oral anatomy and progression of tooth decay were created with the input of content experts. Results: Jawnatomy will be launched in our institution's dentistry and dental hygiene program to support project- and team-based learning. This program will also be introduced to students as a self-directed learning tool to help them practice and strengthen their anatomical knowledge at their own pace. Conclusions: Surveys and focus groups will be conducted to evaluate and further improve the computer program. We believe that Jawnatomy will become an invaluable teaching tool for dental education.

Keywords: Dental Education, Microbiology, Anatomy, Pathology, Health Education

Submitted: February 16, 2021

Revised: May 22, 2021

Accepted: July 4, 2021

\section{Corresponding Author}

Nazlee Sharmin

School of Dentistry, Faculty of Medicine \& Dentistry, College of Health Sciences, University of Alberta, Edmonton Clinic Health Academy, 1140587 Avenue NW, Edmonton, AB T6G 1C9, Canada. Tel: +1-780-492-6428, E-mail: nazlee@ualberta.ca (https://orcid. org/0000-0002-2408-2333)

*These authors contributed equally to this work.

This is an Open Access article distributed under the terms of the Creative Commons Attribution Non-Commercial License (http://creativecommons.org/licenses/by$\mathrm{nc} / 4.0 /$ ) which permits unrestricted non-commercial use, distribution, and reproduction in any medium, provided the original work is properly cited.

(C) 2021 The Korean Society of Medical Informatics

\section{Introduction}

The knowledge of anatomy is integrated with many other disciplines of medical and dental education. Students in dentistry, medicine, and other health professions need to develop a clear spatial understanding of a physiological system to comprehend its composition, orientation, and interaction with surrounding structures. The three-dimensional (3D) conception of anatomical structures forms the foundation of understanding physiology and pathology [1]. Students in the Dentistry and Dental Hygiene Programs at the University of Alberta extensively study dental and oral anatomy, pathology, and oral microbiology. To understand the pathology of a disease or the effect of a localized lesion, a student must have a spatial understanding of the anatomical structures of the mouth. Knowledge of oral anatomy is also required to study 
oral microbiology. Oral health professionals need a detailed understanding of the diversity and function of the oral microbiota in different parts of the mouth. The oral microbiota varies and changes dynamically based on age, sex, genetics, and nutritional habits. Understanding the oral microbiome's localization, function, and gradual transformation is often challenging for students who are only presented with $2 \mathrm{D}$ textbook images.

Wax or ceramic 3D models are traditionally used to teach dental anatomy; however, these static models fail to represent dynamic cellular and physiological mechanisms. Moreover, the structural details of the oral cavity, which are critical for dental education, are often omitted or are presented in insufficient detail in existing models. Educators are now more frequently using Internet-based animations and videos to explain physiological mechanisms. However, a significant drawback of these videos and animations is that learners cannot interact with these modalities, and instructors cannot manipulate the pre-made animations to meet their specific teaching needs.

The recent curricular transformation in dental and medical schools centers around integrating knowledge among disciplines and pedagogical improvement to enhance students' learning experiences [2-4]. Approaches to facilitate studentcentered learning include introducing innovative teaching techniques and blending traditional face-to-face teaching with technology-enhanced learning [5]. In an integrated medical curriculum, vertical integration connects basic and clinical science, while horizontal integration blurs the line between traditionally separated subject areas [6,7].

We developed a computer program called Jawnatomy that displays a human head model. In this model, we aimed to incorporate details of the oral and dental anatomical structures needed for dental education. The program also illustrates the gradual progression of some oral pathologies and the localization of the oral microbiome in different parts of the mouth. Jawnatomy can be used as a teaching and learning tool for anatomy, pathology, and the microbiology of oral structures in an integrated manner.

\section{Description}

Jawnatomy was built as a 3D graphic representation of the human head and oral cavity, including hard and soft tissues. The primary goal of this computer program was to create an integrated platform to teach anatomy, pathology, and microbiology to dental students using a single model. Along with the normal, physiological view of the oral cavity and tooth, Jawnatomy has two modules: pathology and microbiology (Figures 1,2). Users can choose to examine the internal and

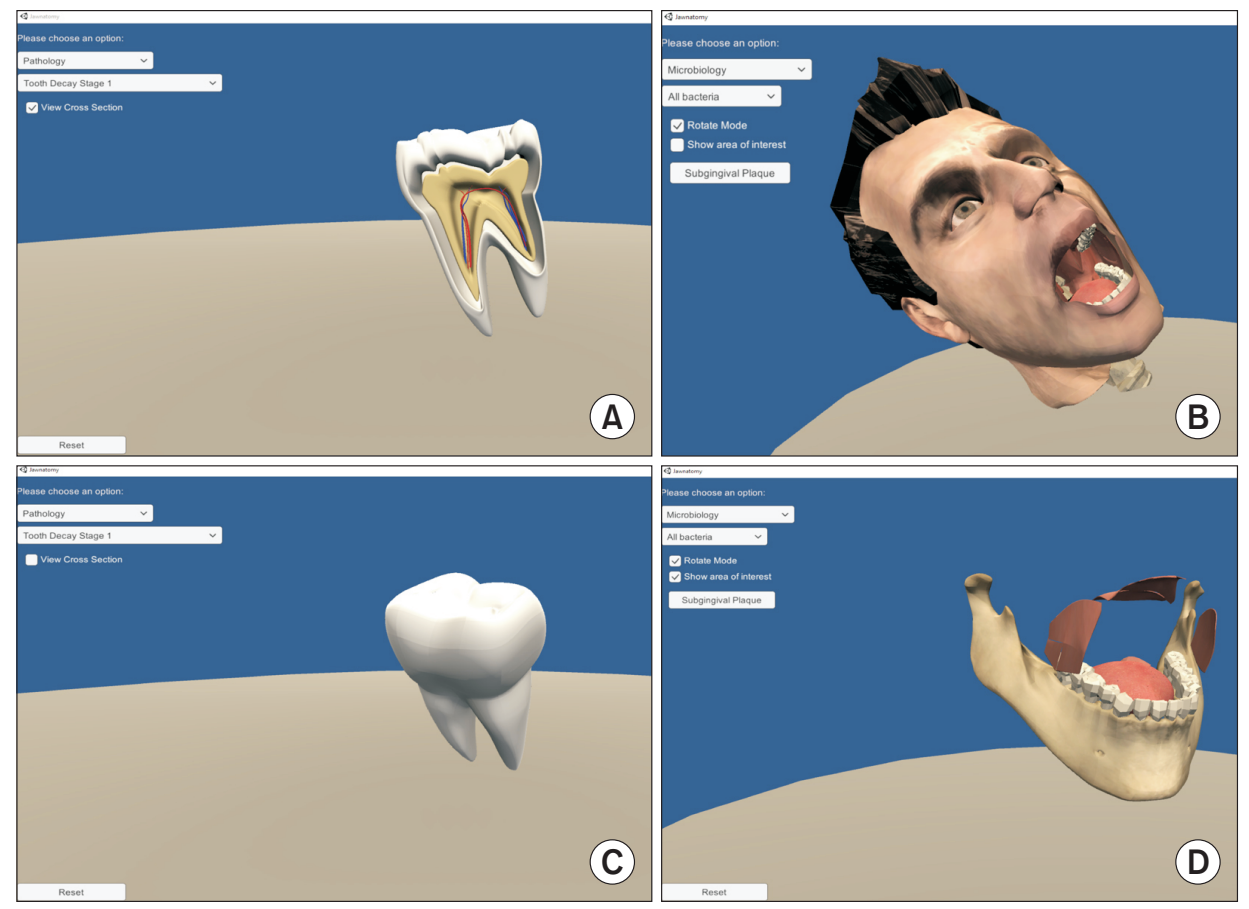

Figure 1. Learning modules of Jawnatomy. Along with a model of the physiological condition, Jawnatomy offers two other learning modules: (A) pathology and (B) microbiology. Jawnatomy allows learners to view the anatomical structure of a healthy tooth in both its surface view (C) and cross-sectional view (A). (D) Students can also remove external facial structures to visualize internal oral structures to learn oral anatomy. 


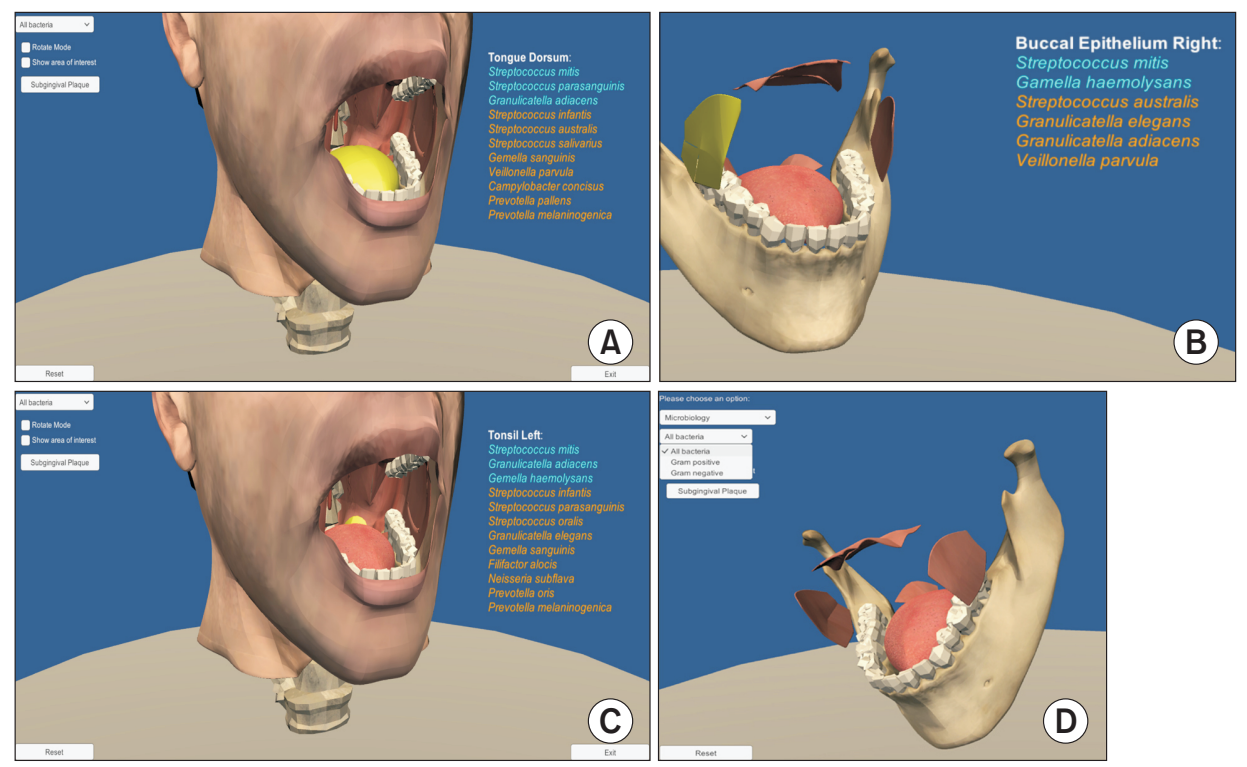

Figure 2. Microbiology module of Jawnatomy. Jawnatomy allows the learner the explore the normal microbial flora of the oral cavity. When selected, each oral cavity region shows the list of bacterial species found in that area. The lists of bacteria colonizing the tongue dorsum, buccal epithelium, and tonsil are shown in (A), (B), and (C), respectively. The list of bacteria is color-coded according to their prevalence, with those in blue being more abundant in that region. (D) Students can also select and group bacteria according to their cell wall properties (Gram-positive and Gram-negative).

external anatomy of a healthy tooth. Jawnatomy displays the gradual progression of tooth decay when the pathology module is selected, starting from a healthy tooth to severe periodontal disease. Learners can visualize disease progression externally, on the surface of a tooth model, and internally from a cross-sectional view of the same tooth (Figure 3 ). The pathological changes that occur during tooth decay are overlaid on the model of a healthy tooth. Users can toggle and visualize the impact of the accumulation of subgingival plaque, gingiva inflammation, and gradual consequential loss of the alveolar bone surrounding the affected tooth (Figure 3). Jawnatomy also enables learners to learn oral and facial anatomy by removing certain facets of the face to visualize internal oral structures (Figure 1D). After introducing the program in-class, lessons and projects will be designed to enhance students' confidence in succeeding if they exert effort. At the end of the course, surveys and focus groups will be conducted to evaluate the effectiveness of Jawnatomy.

In the microbiology module of Jawnatomy, learners can explore the normal microbial flora in different locations of the healthy oral cavity. Students can interact with various parts of the oral cavity to investigate bacterial colonization. When selected, each region shows the list of bacterial species typically found in that region. The bacterial list is colorcoded according to their prevalence and grouped into Grampositive and Gram-negative bacteria (Figure 2). The authors prepared the location-specific list of bacteria based on the published literature $[8,9]$.

Blender [10], a 3D computer graphics software, was used to create the tooth, surrounding oral structures, and facial model for Jawnatomy. The same software was used to develop the cross-sections and the different pathological states of the tooth, gingiva (gum), and alveolar bone. The authors agreed upon the anatomical details needed for teaching in dentistry and dental hygiene programs. The oral anatomy and pathology graphics were built under the supervision of content experts (AC and NS). Regular meetings were held between content experts and graphic designers to review and modify the anatomical structures and disease states for accuracy. Unity 3D [11] was used to incorporate interactivity, enabling users to magnify and rotate the models, toggle between cross-sections, stages of periodontitis, and investigate the localized microbial communities within the open mouth of the 3D head model. Jawnatomy is packaged as an executable file, which instructors supply to students. To run Jawnatomy in Windows or Mac OS, the user needs to unzip the file and start the executable file named "Jawnatomy."

Several educational theories guided the development of Jawnatomy. Learning anatomy requires comprehension of the $3 \mathrm{D}$ anatomical structures and the structure-function relationships in a biological system [12]. Recognizing that students often struggle with the formation of complex mental models that require the integration of $3 \mathrm{D}$ structures and the changes that occur in pathological states, Jawnatomy 

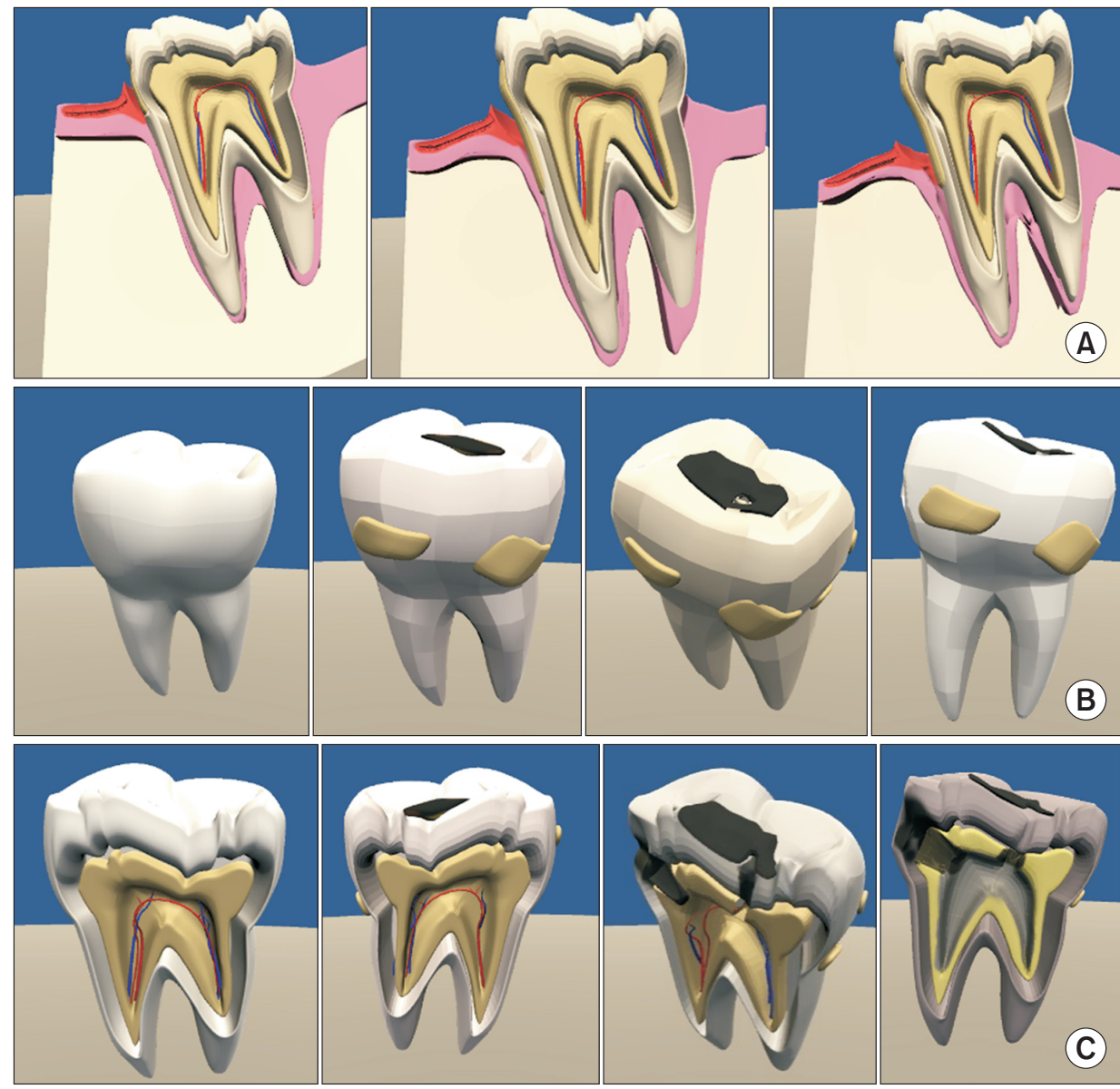

Figure 3. Pathology module of Jawnatomy. The pathology module of Jawnatomy allows learners to visualize the pathological processes observed in $(A)$ periodontal disease and $(B, C)$ dental caries. Periodontal disease is a chronic inflammatory disease that starts with bacterial plaque accumulation in the subgingival region. (A) Students can observe the progression of gingival inflammation and gradual loss of underlying alveolar bone to understand the development of periodontal disease. (B) Learners can also visualize plaque accumulation and dental caries formation on a molar tooth. They can rotate the tooth model to different angles and magnify areas to observe structural details. (C) Students can switch to the cross-sectional mode to analyze the effect of dental caries on the tooth's internal structure. This module allows students to understand the gradual progression of the disease and compare it with healthy teeth and oral structures.

was developed to reduce the cognitive load experienced by students during the learning process. Cognitive load theory is based on the premise that learning becomes difficult when the brain's limited resources are taxed due to intrinsic and extrinsic loads [13]. The inherent complexity and the nature of the content contribute to the intrinsic load, which is not easily altered. The extrinsic load, however, comes from the way the material is presented [13], and Jawnatomy reduces this extrinsic load by helping students form 3D mental models and visualize the interactions that can occur between the oral anatomy and microbiota.

Motivation is an essential component of learning behavior. Studies have found that students with high motivation show more exploratory learning behaviors [14]. Using Keller's attention, relevance, confidence, and satisfaction (ARCS) model [15], Jawnatomy was developed to increase student motivation and interaction with the material. According to Keller's ARCS model, students are motivated to learn when if the material (1) captures and sustains students' attention; (2) explains the subject's relevance; (3) increases students' confidence that they can succeed if they exert effort; and (4) ensures overall student satisfaction [16]. Attention can be earned by perceptual arousal, inquiry arousal, and variability $[15,17]$. Jawnatomy includes interactive 3D computer graphics to capture students' visual attention.

\section{Discussion}

Jawnatomy was designed to (1) facilitate the horizontal integration of oral anatomy, pathology, and microbiology in 
dental education, (2) increase student motivation, and (3) reduce the extrinsic load of learning and integrating different disciplines. This program will be introduced to first-year students in the dentistry and dental hygiene programs. In addition to regular classroom teaching, Jawnatomy will enable in-class project- and team-based learning by facilitating peer discussions and interactions, supported by Bandura's social learning theory [18]. Jawnatomy will also be made available to students as a self-directed learning tool to help them strengthen their anatomical knowledge at their own pace. Students in dentistry and dental hygiene programs are emerging adult learners. Knowles' theory of andragogy emphasizes that adults are self-directed in their learning [19]. Jawnatomy gives learners control over their own learning by allowing them to access the material when they are most ready to learn.

Computer-aided programs are valuable and have great potential in medical and dental education [20,21]. The effectiveness of several computer-based teaching tools, games, and simulations has been demonstrated through improvements in student satisfaction, in-class participation [22], and academic performance [23,24]. Jawnatomy enables students to visualize $3 \mathrm{D}$ oral structures and the dynamic process of some oral pathologies, thereby improving their understanding of anatomy and pathology and facilitating the retention of visually learned information [12].

Although Jawnatomy and other technologies can improve learning experiences, they can also cause restrictions for students who are less advantaged. The students at the School of Dentistry must have a computer or similar personal device. However, not all students have the privilege to access the up-to-date computers necessary to run programs like Jawnatomy. Despite this limitation, we believe that Jawnatomy will become a valuable addition to dental education. We will continue to update and expand this computer program based on students' feedback.

\section{Conflict of Interest}

No potential conflict of interest relevant to this article was reported.

\section{ORCID}

Ava K. Chow (https://orcid.org/0000-0002-1972-0310)

Nazlee Sharmin (https://orcid.org/0000-0002-2408-2333)

\section{References}

1. Alraddadi A. Literature review of anatomical variations: clinical significance, identification approach, and teaching strategies. Cureus 2021;13(4):e14451.

2. Han ER, Yeo S, Kim MJ, Lee YH, Park KH, Roh H. Medical education trends for future physicians in the era of advanced technology and artificial intelligence: an integrative review. BMC Med Educ 2019;19(1):460.

3. Harden RM. Ten key features of the future medical school-not an impossible dream. Med Teach 2018;40(10): 1010-5.

4. Frenk J, Chen L, Bhutta ZA, Cohen J, Crisp N, Evans T, et al. Health professionals for a new century: transforming education to strengthen health systems in an interdependent world. Lancet 2010;376(9756):1923-58.

5. Grainger R, Liu Q, Geertshuis S. Learning technologies: a medium for the transformation of medical education? Med Educ 2021;55(1):23-9.

6. Dahle LO, Brynhildsen J, Behrbohm Fallsberg M, Rundquist I, Hammar M. Pros and cons of vertical integration between clinical medicine and basic science within a problem-based undergraduate medical curriculum: examples and experiences from Linköping, Sweden. Med Teach 2002;24(3):280-5.

7. Brauer DG, Ferguson KJ. The integrated curriculum in medical education: AMEE Guide No. 96. Med Teach 2015;37(4):312-22.

8. Aas JA, Paster BJ, Stokes LN, Olsen I, Dewhirst FE. Defining the normal bacterial flora of the oral cavity. J Clin Microbiol 2005;43(11):5721-32.

9. Wilbert SA, Mark Welch JL, Borisy GG. Spatial ecology of the human tongue dorsum microbiome. Cell Rep 2020;30(12):4003-4015.e3.

10. Blender: a 3D modelling and rendering package [Internet]. Amsterdam, Netherlands: Stichting Blender Foundation; 2018 [cited at 2021 Sep 30]. Available from: http://www.blender.org.

11. Unity: using the UI tools [Internet]. San Francisco (CA): Unity Technologies; c2021 [cited at 2021 Sep 30]. Available from: https://unity.com/.

12. Khalil MK, Paas F, Johnson TE, Payer AF. Design of interactive and dynamic anatomical visualizations: the implication of cognitive load theory. Anat Rec B New Anat 2005;286(1):15-20.

13. Sweller J. Cognitive load theory and educational technology. Educ Technol Res Dev 2020;68(1):1-16.

14. Martens R, Gulikers J, Bastiaens T. The impact of in- 
trinsic motivation on e-learning in authentic computer tasks. J Comput Assist Learn 2004;20(5):368-76.

15. Keller JM. Motivational design for learning and performance: the ARCS model approach. New York (NY): Springer; 2010.

16. Li K, Keller JM. Use of the ARCS model in education: a literature review. Computers \& Education 2018;122:54-62.

17. Milman NB, Wessmiller J. Motivating the online learner using Keller's ARCS model. Distance Learn 2016;13(2): 67-71.

18. Bandura A. Social learning theory. Englewood Cliffs (NJ): Prentice-Hall; 1977.

19. Knowles MS. Self-directed learning: a guide for learners and teachers. New York (NY): Association Press; 1975.

20. Azer SA. A multimedia CD-ROM tool to improve student understanding of bile salts and bilirubin metabolism: evaluation of its use in a medical hybrid PBL course. Adv Physiol Educ 2005;29(1):40-50.
21. Rosenberg H, Grad HA, Matear DW. The effectiveness of computer-aided, self-instructional programs in dental education: a systematic review of the literature. J Dent Educ 2003;67(5):524-32.

22. Revell SM, McCurry MK. Engaging millennial learners: effectiveness of personal response system technology with nursing students in small and large classrooms. J Nurs Educ 2010;49(5):272-5.

23. Janssen A, Shaw T, Goodyear P, Kerfoot BP, Bryce D. A little healthy competition: using mixed methods to pilot a team-based digital game for boosting medical student engagement with anatomy and histology content. BMC Med Educ 2015;15:173.

24. Thompson ME, Ford R, Webster A. Effectiveness of interactive, online games in learning neuroscience and students' perception of the games as learning tools: a pre-experimental study. J Allied Health 2011;40(3):1505 . 